\title{
Satellite drag effects due to uplifted oxygen neutrals during super magnetic storms
}

\author{
Gurbax S. Lakhina ${ }^{1}$ and Bruce T. Tsurutani ${ }^{2}$ \\ ${ }^{1}$ Indian Institute of Geomagnetism, New Panvel (W), Navi Mumbai, India \\ ${ }^{2}$ Jet Propulsion Laboratory, California Institute of Technology, Pasadena, CA, USA \\ Correspondence: Gurbax S. Lakhina (gslakhina@gmail.com)
}

Received: 28 June 2017 - Discussion started: 19 July 2017

Revised: 15 November 2017 - Accepted: 17 November 2017 - Published: 15 December 2017

\begin{abstract}
During intense magnetic storms, prompt penetration electric fields (PPEFs) through $E \times B$ forces near the magnetic equator uplift the dayside ionosphere. This effect has been called the "dayside super-fountain effect". Ionneutral drag forces between the upward moving $\mathrm{O}^{+}$(oxygen ions) and oxygen neutrals will elevate the oxygen atoms to higher altitudes. This paper gives a linear calculation indicating how serious the effect may be during an 1859-type (Carrington) superstorm. It is concluded that the oxygen neutral densities produced at low-Earth-orbiting (LEO) satellite altitudes may be sufficiently high to present severe satellite drag. It is estimated that with a prompt penetrating electric field of $\sim 20 \mathrm{mV} \mathrm{m}^{-1}$ turned on for $20 \mathrm{~min}$, the $\mathrm{O}$ atoms and $\mathrm{O}^{+}$ions are uplifted to $850 \mathrm{~km}$ where they produce about 40-times-greater satellite drag per unit mass than normal. Stronger electric fields will presumably lead to greater uplifted mass.
\end{abstract}

\section{Introduction}

Prompt penetration of interplanetary electric fields (IEFs) to the dayside equatorial ionosphere has been known for a long time (Obayashi, 1967; Nishida, 1968; Kelley et al., 1979). It has been shown that during super magnetic storms, defined as storms with Dst $<-250 \mathrm{nT}$ (Tsurutani et al., 1992; Echer et al., 2008), the prompt penetrating electric fields (PPEFs) associated with large IEF intervals can last for more than several hours in the ionosphere (Tsurutani et al., 2004; Maruyama et al., 2004; Mannucci et al., 2005; Sahai et al., 2005; Huang et al., 2005). Intense dawn-to-dusk (eastward viewing from the northern hemisphere) PPEFs uplift the dayside plasma to higher altitudes and magnetic latitudes due to $E \times B$ drifts (Tsurutani et al., 2004, 2008; Mannucci et al., 2005; Verkhoglyadova et al., 2007). The ionospheric electron-ion recombination rate is much slower at higher altitudes (Tsurutani et al., 2005); thus the "old" uplifted ionosphere is more or less stable. Solar photoionization replaces the displaced plasma at lower altitudes, increasing the total electron content (TEC) of the ionosphere. After the PPEF subsides, the plasma flows down along the magnetic field lines to even greater magnetic latitudes. This overall process is named as the "dayside super-fountain effect".

During superstorms, the vertical TEC values are found to increase to several times quiet-time values across the dayside ionosphere at low and middle latitudes (Heelis et al., 2009). This has been empirically observed by satellite and from ground-based GPS (Global Positioning System) receivers. Apart from the dayside super-fountain effect, which occurs during the first few hours of a superstorm, there is another mechanism called the "disturbance dynamo" (Blanc and Richmond, 1980; Fuller-Rowell et al., 1997). The latter is caused by particle precipitation and atmosphere heating in the auroral zone during the superstorms and consequential equatorward-directed neutral winds due to this heating process. However, all superstorms are not alike as they have different peak intensities and associated convection electric fields (Gonzalez et al., 1994). Therefore, the PPEFs produce different effects in terms of TEC enhancements, poleward-shifting of equatorial ionization anomaly (EIA) peaks (Namba and Maeda, 1939; Appleton, 1946) from the typical quiet-time positions at $\sim \pm 10^{\circ}$, compositional changes, etc. Studies of the Bastille Day (15 July 2000) superstorm (Basu et al., 2001, 2007; Kil et al., 2003, Yin et 
al., 2004; Rishbeth et al., 2010), the Halloween (30 October 2003) superstorm (Tsurutani et al., 2004, 2007, 2008; Mannucci et al., 2005; Verkhoglyadova et al., 2007), and some other superstorm events (Foster et al., 2004; Lin et al., 2005; Immel et al., 2005; Mannucci et al., 2008, 2009) clearly illustrate the above point.

Using a modified version of the low- to mid-latitude ionosphere code SAMI2 (Sami2 is Another Model of the Ionosphere) of the Naval Research Laboratory (NRL) (Huba et al., 2000, 2002), Tsurutani et al. (2007) have studied the $\mathrm{O}^{+}$ion uplift in the dayside ionosphere due to first $\sim 2 \mathrm{~h}$ of PPEFs during the 30 October 2003 (Halloween) superstorm. Their simulations clearly show the dayside $\mathrm{O}^{+}$ions uplifted to higher altitudes $(\sim 600 \mathrm{~km})$ and higher magnetic latitudes (MLATs) $\left(\sim \pm 25\right.$ to $\left.30^{\circ}\right)$, forming highly displaced EIA peaks. The rapid upward drift of the $\mathrm{O}^{+}$ions causes neutral oxygen $(\mathrm{O})$ uplift due to ion-neutral drag forces. They also find that above $\sim 400 \mathrm{~km}$ altitude, the neutral oxygen atom densities within the displaced EIAs increase substantially over their quiet-time values.

Recently, Tsurutani et al. (2012) have modelled the 12 September 1859 Carrington storm using the modified SAMI2 code (Verkhoglyadova et al., 2007, 2008). This superstorm's intensity was the highest in recorded history, Dst -1760 nT (Tsurutani et al., 2003; Lakhina et al. 2012). The storm-time electric field has been estimated to have been $\sim 20 \mathrm{mV} \mathrm{m}^{-1}$. Similar features to the 30 October 2003 storm were found, but all effects were more severe. The EIAs were found to be located at $\sim 500$ to $900 \mathrm{~km}$ altitude with broad peaks located at $\sim \pm 25$ to $40^{\circ}$ MLAT. In this paper, we study the uplift of neutral oxygen atoms due to the ion-neutral drag force during an 1859-type superstorm. The possible satellite drag effects on low-Earth-orbiting (LEO) satellites will be discussed.

\section{Change in neutral $\mathrm{O}$-atom densities due to ion-neutral drag}

When $\mathrm{O}^{+}$ions drift rapidly upwards through the neutral atmosphere (under the influence of an $E \times B$ force associated with the PPEFs during an 1859-type superstorm), they exert an ion-neutral drag force on the neutral atoms and will uplift them (Tsurutani et al., 2007). A simplified ion-neutral momentum exchange is given by (Baron and Wand, 1983; Kosch et al., 2001)

$$
\frac{\partial U}{\partial t}=\frac{1}{\tau_{\text {in }}}\left(V_{\mathrm{d}}-U\right),
$$

where $U$ is the vertical speed of the neutral oxygen atom due to ion-neutral drag force, $V_{\mathrm{d}}=E \times B / B^{2}$ is the $\mathrm{O}^{+}$vertical drift due to the $E \times B$ force, and $\tau_{\text {in }}$ is the ion-neutral coupling time constant (Killeen et al., 1984) given by

$\tau_{\text {in }}=\frac{n_{0}}{n_{i} v_{\text {in }}}$.
In Eq. (2), $n_{\mathrm{o}}$ is the neutral oxygen atom density, $n_{\mathrm{i}}$ is the $\mathrm{O}^{+}$ion density, and $v_{\text {in }}$ is the ion-neutral collision frequency.

Following Tsurutani et al. (2007), we calculate the ionneutral coupling time, $\tau_{\text {in }}$, for a representative altitude of $\sim 340 \mathrm{~km}$. This reference level was chosen because it is near the equatorial ionization (EIA) density peak location where the ion-neutral drag is expected to be approximately a maximum (Tsurutani et. al., 2007). We obtain $v_{\text {in }}$ from the expression given by Bailey and Balan (1996), i.e. $v_{\text {in }}=4.45 \times 10^{-11} \cdot n_{\mathrm{o}} \cdot T^{1 / 2} \cdot\left(1.04-0.067 \log _{10} T\right)^{2}$, where $T$ is average of the $\mathrm{O}$ and $\mathrm{O}^{+}$temperatures. Using $\mathrm{O}$ and $\mathrm{O}^{+}$temperatures of $\sim 10^{3} \mathrm{~K}$ and noon-time densities of $n_{\mathrm{o}}=1.1 \times 10^{9} \mathrm{~cm}^{-3}$ and $n_{\mathrm{i}}=3.5 \times 10^{6} \mathrm{~cm}^{-3}$, we get $\tau_{\text {in }} \sim 5 \mathrm{~min}$.

Considering the initial (boundary) conditions at the reference altitude $(z \sim 340 \mathrm{~km})$ as $U=0$ at $t=0$, the solution to Eq. (1) can be written as

$U=V_{\mathrm{d}}\left[1-\exp \left(t / \tau_{\text {in }}\right)\right]$

The uplift of the neutrals will cause changes in their density with altitude, $z$. To first order, the continuity equation for $\mathrm{O}$ can be written as

$\frac{\partial n}{\partial t}+U \frac{\partial n_{\mathrm{o}}}{\partial z}=0$

On substituting $U$ from Eq. (3) and integrating Eq. (4) with the boundary condition that $n=n_{\mathrm{o}}$ at $t=0$, we get the change in neutral density as

$\delta n=\frac{V_{\mathrm{d}}}{H}\left[t-\tau_{\text {in }}\left(1-\exp \left(-t / \tau_{\text {in }}\right)\right)\right]$,

where $\delta n=\left(n-n_{\mathrm{o}}\right) / n_{\mathrm{o}}$, and $H=\left(\frac{1}{n_{\mathrm{o}}} \frac{\partial n_{\mathrm{o}}}{\partial z}\right)^{-1}$ is the oxygen neutral scale height. Equation (5) implies that neutral density time dependence at progressively higher altitude layers will be affected by the arrival of neutrals uplifted from below due to the ion-neutral drag. We must emphasize that Eq. (5) gives only the first-order estimates. Implicitly it is assumed that the pressure gradient and gravity effects balance each other during the uplift. For more accurate estimates, one has to consider the nonlinear coupling terms along with the inclusion of gravity, pressure gradients, viscosity, advection of the Oatom flow (i.e. the $U \cdot \nabla U$ term which has been neglected in Eq. 1), and the effects of heating and expansion during the uplift process. The decrease of the ambient oxygen density is also not taken into account in the above estimate. All of these will have to be considered in a fully self-consistent nonlinear code.

\section{Satellite drag due to $\mathrm{O}^{+}$and $\mathrm{O}$ enhanced fluxes during superstorms}

Drag force per unit mass on a satellite moving through the Earth's atmosphere is given by (Chopra, 1961; Gaposchkin 
and Coster, 1988; Moe and Moe, 2005; Pardini et al., 2010; $\mathrm{Li}, 2011)$

$$
F=\frac{1}{2} C_{\mathrm{D}}\left(\frac{A}{M}\right)(m n) V_{\mathrm{s}}^{2}+\frac{1}{2} C_{\mathrm{Di}}\left(\frac{A}{M}\right)\left(m_{i} n\right) V_{\mathrm{s}}^{2},
$$

where $C_{\mathrm{D}}$ represents the neutral drag coefficient due to impingement of $\mathrm{O}$ atoms on the satellite surface and $C_{\mathrm{Di}}$ is the ion (Coulomb) drag coefficient due to scattering of $\mathrm{O}^{+}$ions by the satellite potential (a satellite moving in an ionized atmosphere acquires an electric charge mainly through collisions with charged particles), $m$ is the mass of neutral atom $(\mathrm{O})$, and $m_{\mathrm{i}}$ is the mass of $\mathrm{O}^{+}$ions, $A$ is the satellite cross-section area perpendicular to the velocity vector, $M$ the mass of the satellite, and $V_{\mathrm{s}}$ is the satellite velocity with respect to the atmosphere. The drag coefficients $C_{\mathrm{D}}$ and $C_{\mathrm{Di}}$ have been discussed theoretically and calculated from empirical observations of satellite deceleration and other data by many authors (Chopra, 1961; Cook, 1965, 1966; Fournier, 1970; Gaposchkin and Coster, 1988; Moe and Moe, 2005; Moe et al., 1998; Pardini et al., 2010; Li, 2011). The information on the gas-surface interaction on the surface of the satellite and contamination of the satellite surface due to the absorbed atomic oxygen is essential to accurately determine the drag coefficients (Chopra, 1961; Cook, 1965, 1966; Pardini et al., 2010). Various studies (Chopra, 1961; Cook, 1965, 1966; Pardini et al., 2010) show that, for spherically or cylindrically shaped satellites, the neutral drag coefficient $C_{\mathrm{D}}$ varies from $\sim 2.0$ to 2.8 between altitudes of $z=\sim 200$ to $800 \mathrm{~km}$ with a most commonly used value of $C_{\mathrm{D}}=2$. In contrast the Coulomb drag coefficient $C_{\mathrm{Di}}$ varies widely with altitude, e.g. $C_{\mathrm{Di}}=7 \times 10^{-5}, 0.32$ and 6.1 at $z=250,500$ and $800 \mathrm{~km}$, respectively (Chopra, 1961; Li, 2011). The area-to-mass ratio of the satellite, $A / M$, can have values of $\sim 0.038-0.285 \mathrm{~cm}^{2} \mathrm{~g}^{-1}$, which obviously varies from satellite to satellite. A typical value of a satellite payload is $A / M=0.1 \mathrm{~cm}^{2} \mathrm{~g}^{-1}$ (Gaposchkin and Coster, 1988; Pardini et al., 2010), which we will use in our following calculations. A typical value for the LEO satellite speed with respect to the atmosphere is $V_{\mathrm{s}} \sim 7.5 \mathrm{~km} \mathrm{~s}^{-1}$. Thus our calculations of $n_{\mathrm{o}}$ (O densities) during superstorms can be used to calculate the drag force on LEO satellites by using Eq. (5).

In Table 1, for the super magnetic storm of 1-2 September 1859 , we give the estimates of altitude, $z$, reached by uplifted $\mathrm{O}$ atoms from the integration of Eq. (3) (column 2), change in $\mathrm{O}$ density from Eq. (5), $\delta n$ (column 3), the Coulomb drag coefficient, $C_{\mathrm{Di}}$ extrapolated from the values given by Chopra (1961) and $\mathrm{Li}$ (2011) (column 4), and the drag force per unit mass, $F$ calculated from Eq. (6) (column 5) for various values of time, $t$, after the application of $20 \mathrm{mV} \mathrm{m}^{-1}$ PPEF in the equatorial ionosphere (with a constant $B_{0}=0.35 \times 10^{-4} \mathrm{~T}$ ) (column 1). A constant neutral drag coefficient $C_{\mathrm{D}}=2.0$, $V_{\mathrm{s}}=7.5 \mathrm{~km} \mathrm{~s}^{-1}$, and $A / M=0.1 \mathrm{~cm}^{2} \mathrm{~g}^{-1}$ and for a scale height of $H \sim 50 \mathrm{~km}$ are assumed. The reference altitude is taken at $z=340 \mathrm{~km}$ with the oxygen atom $(\mathrm{O})$ mass density
Table 1. Estimates of the altitude, $z$, attained by uplifted $\mathrm{O}$ atoms, relative change in $\mathrm{O}$ density, $\delta n$, Coulomb drag coefficient (extrapolated from Chopra, 1961, and $\mathrm{Li}, 2011), C_{\mathrm{Di}}$, drag force per unit mass on satellite, $F$, at different times, $t$, after the onset of a PPEF of $20 \mathrm{mV} \mathrm{m}^{-1}$ in a Carrington (1-2 September 1859) type super magnetic storm. The reference altitude is taken at $z=340 \mathrm{~km}$ with the Earth's magnetic field, $B_{0}=0.35 \times 10^{-4} T$, and the oxygen atom $(\mathrm{O})$ mass density $m n_{\mathrm{O}}=2.94361 \times 10^{-14} \mathrm{~g} \mathrm{~cm}^{-3}$. The background neutral $\mathrm{O}$ density is assumed to decrease exponentially with altitude with a scale height of $H=50 \mathrm{~km}$. The other parameters are neutral drag coefficient $C_{\mathrm{D}}=2.0, V_{\mathrm{s}}=7.5 \mathrm{~km} \mathrm{~s}^{-1}$, and areato-mass ratio of satellite, $A / M=0.1 \mathrm{~cm}^{2} \mathrm{~g}^{-1}$, and the scale height, $H=50 \mathrm{~km}$.

\begin{tabular}{lcrrc}
\hline $\begin{array}{l}t \text { (time } \\
\text { after onset } \\
\text { of PPEFs, } \\
\text { in s) }\end{array}$ & $\begin{array}{c}z \text { (altitude } \\
\text { attained, } \\
\text { in km) }\end{array}$ & $\begin{array}{r}\delta n \text { (change } \\
\text { in O density) }\end{array}$ & $\begin{array}{r}C_{\mathrm{Di}} \text { (Coulomb } \\
\text { drag coefficient) }\end{array}$ & $\begin{array}{c}F \text { (drag } \\
\text { force per } \\
\text { unit mass, } \\
\text { in } \mathrm{cm} \mathrm{s}^{-2} \text { ) }\end{array}$ \\
\hline 0 & 340 & 0 & 0.01 & 0.0017 \\
300 & 402 & 1.26 & 0.15 & 0.0028 \\
600 & 534 & 3.88 & 0.32 & 0.0075 \\
900 & 690 & 7.01 & 1.43 & 0.0199 \\
1200 & 856 & 10.32 & 6.1 & 0.0692 \\
\hline
\end{tabular}

$m n_{\mathrm{o}}=2.94361 \times 10^{-14} \mathrm{~g} \mathrm{~cm}^{-3}$. The background neutral $\mathrm{O}$ density is assumed to decrease exponentially with altitude with a scale height of $H=50 \mathrm{~km}$. It is interesting to note that in just $20 \mathrm{~min}(t=1200 \mathrm{~s})$, the uplifted $\mathrm{O}$ atoms reach an altitude of $z=856 \mathrm{~km}$ from the reference altitude of $340 \mathrm{~km}$ at $t=0$. The drag force per unit mass on the satellite is $F=0.0017 \mathrm{~cm} \mathrm{~s}^{-2}$ at $z=340 \mathrm{~km}(t=0)$ and it increases to $F=0.0692 \mathrm{~cm} \mathrm{~s}^{-2}$ at an altitude of $z=856 \mathrm{~km}(t=1200 \mathrm{~s})$ - an increase of more than 40 times! As one can see from column 4, the Coulomb drag coefficient increases with altitude. Therefore, its contribution to $F$ increases as $\mathrm{O}^{+}$ions and $\mathrm{O}$ neutral atoms are uplifted by the action of PPEFs via the $E \times B$ force. We find that Coulomb drag dominates over the neutral drag at altitudes above $\sim 750 \mathrm{~km}$.

\section{Conclusions}

We have done preliminary estimates of the drag force per unit mass on typical low-Earth-orbiting satellites moving through the ionosphere during super magnetic storms, like the Carrington 1-2 September 1859 event. A simple firstorder model is employed to calculate the changes in density of the neutral $\mathrm{O}$ atoms at different altitudes due to ion-neutral drag between the uplifted $\mathrm{O}^{+}$ions and $\mathrm{O}$ neutral atoms. The uplifted $\mathrm{O}^{+}$ion speeds result from the $E \times B$ force from the PPEFs. It should be noted that there is no expansion of the column of gas from 340 to $850 \mathrm{~km}$. Rather, the entire column of atmosphere is uplifted by the $E \times B$ force. There may be a slight increase in the temperature of the $\mathrm{O}$ atoms due to the friction with $\mathrm{O}^{+}$ions. Consequently, as the pressure remains the same or is slightly increased, it will more or less balance 
the gravity during the first 20 min or so. Eventually, the nonlinear coupling, gravity, pressure gradients, advection of the $\mathrm{O}$-atom flow arising from divergence terms, and viscosity effects will dominate and will stop the uplift of the neutrals. Therefore, this simple model may be reasonable for the first $\sim 20$ min after the onset of the PPEF in the ionosphere.

We may point out that the nightside ionosphere may be depressed due to change of sign of $E \times B$ drift (i.e. downward drift instead of uplift). However, as the neutral O-atom density will increase sharply at lower altitudes, the relative change in O-atom density due to ion-neutral drag force would be relatively small, and that too limited to altitudes lower than the reference level. Since at the higher altitudes, the neutral $\mathrm{O}$ density is expected to remain more or less unchanged, the satellite on the night side will not feel any extra drag force due to $E \times B$ drift. Therefore, we do not expect that the nightside ionosphere can compensate for the extra dayside satellite drag due to uplifted $\mathrm{O}$ atom over a satellite orbit.

In this paper, we have not considered the effect of Joule heating in increasing the neutral densities and temperatures during super magnetic storms. The Joule heating occurs in the auroral regions, but it may come down to lower latitudes during superstorms. Therefore, the effects due to Joule heating are important primarily at high latitudes initially, and such increases are expected to manifest at equatorial latitudes after 2-3 h or more. However, our mechanism will occur near the equator and at middle latitudes. At middle latitudes the two mechanisms would most likely merge. Furthermore, it can be estimated that an increase in neutrals temperature of $200 \mathrm{~K}$, say from 800 to $1000 \mathrm{~K}$, will cause a factor-of- 10 increase in the $\mathrm{O}$ density at $850 \mathrm{~km}$ just by the scale height effect. A $400{ }^{\circ} \mathrm{K}$ increase in temperature would increase the $\mathrm{O}$ density by a factor of 100 at $850 \mathrm{~km}$. This is the same increase that is obtained from our proposed mechanism. It should be remembered that the process of uplift of neutral $\mathrm{O}$ atoms due to penetration electric fields during super magnetic storms occurs during the span of $20 \mathrm{~min}$. In reality, an increase in the temperature of neutrals by 200 to $400 \mathrm{~K}$ in $20 \mathrm{~min}$ at equatorial latitudes by the Joule heating or any other process during magnetic storms has not been observed.

It is shown that in just $\sim 20 \mathrm{~min}$ after the action of a $20 \mathrm{mV} \mathrm{m}^{-1}$ PPEF in the equatorial ionosphere, the neutral $\mathrm{O}$ atoms (and also $\mathrm{O}^{+}$ions) are uplifted to an altitude of $z=856 \mathrm{~km}$ from a reference level of $z=340 \mathrm{~km}$. A typical spherically or cylindrically shaped satellite moving through the ionosphere at altitudes of $\sim 850 \mathrm{~km}$ would experience 40 times more drag per unit mass than normal. If larger IEFs associated with either superflares (see Maehara et al., 2012; Tsurutani and Lakhina, 2014) or during extreme magnetic storms stronger than the Carrington storm (Vasyliunas, 2011; Lakhina and Tsurutani, 2016) are imposed on the magnetosphere, then larger-scale PPEFs will be imposed on the dayside ionosphere with even greater O-atom uplift. We do not know when such cases can occur at the Earth, but we cannot exclude the possibility at this time.

Data availability. Data used in computing Table 1 are available in the published literature quoted in the paper.

Competing interests. The authors declare that they have no conflict of interest.

Special issue statement. This article is part of the special issue "Nonlinear Waves and Chaos", which resulted from 10th International Nonlinear Wave and Chaos Workshop (NWCW17), San Diego, United States, 20-24 March 2017.

Acknowledgements. A portion of this work was done at NASA Jet Propulsion Laboratory, California Institute of Technology, Pasadena, CA, USA. Gurbax S. Lakhina thanks the National Science Academy, India, for support under the NASI-Platinum Jubilee Senior Scientist Scheme.

Edited by: George Morales

Reviewed by: Yasuhito Narita and two anonymous referees

\section{References}

Appleton, E. V.: Two anomalies in the ionosphere, Nature, 157, 691 https://doi.org/10.1038/157691a0, 1946.

Bailey, G. J. and Balan, N.: A low-latitude ionosphereplasmasphere model, in: STEP: Handbook of Ionospheric Models, edited by: Schunk, R. W., Utah State Univ., Logan, Utah, p. 173, 1996.

Baron, M. J. and Wand, R. H.: F region ion temperature enhancements resulting from Joule heating, J. Geophys. Res., 88, 41144118, 1983.

Basu, S., Basu, S., Groves, K. M., Yeh, H.-C., Su, S.-Y., Rich, F. J., Sultan, P. J., and Keskinen, M. J.: Response of the equatorial ionosphere in the south Atlantic region to the great magnetic Storm of July 15, 2000, Geophys. Res. Lett., 28, 3577-3580, 2001.

Basu, S., Basu, S., Rich, F. J., Groves, K. M., MacKenzie, E., Coker, C., Sahai, Y., Fagundes, P. R., and Becker-Guedes, F.: Response of the equatorial ionosphere at dusk to penetration electric fields during intense magnetic storms, J. Geophys. Res., 112, A08308, https://doi.org/10.1029/2006JA012192, 2007.

Blanc, M. and Richmond, A. D.: The ionospheric disturbance dynamo, J. Geophys. Res., 86, 1669, https://doi.org/10.1029/JA085iA04p01669, 1980.

Chopra, K. P.: Interactions of rapidly moving bodies in terrestrial atmosphere, Rev. Mod. Phys., 33, 153-198, 1961.

Cook, G. E.: Satellite drag coefficients, Planet. Space Sci., 13, 929_ 946, 1965.

Cook, G. E.: Drag coefficients of spherical satellites, Ann. Geophys., 22, 53-64, 1966. 
Echer, E., Gonzalez, W. D., and Tsurutani, B. T.: Interplanetary conditions leading to superintense geomagnetic storms (Dst $<-250$ nT) during solar cycle 23, Geophys. Res. Lett., 35, L06S03, https://doi.org/10.1029/2007GL031755, 2008.

Foster, J. C., Coster, A. J., Erickson, P. J., Rich, F. J., and Sandel, B. R.: Stormtime observations of the flux of plasmaspheric ions to the dayside cusp/magnetopause, Geophys. Res. Lett., 31, L08809, https://doi.org/10.1029/2004GL020082, 2004.

Fournier, G.: Electric drag, Planet. Space Sci., 18, 1035-1041, 1970.

Fuller-Rowell, T. M., Codrescu, M. V., and Richmond, A. D.: How does the thermosphere and ionosphere react to a geomagnetic storm?, in: Magnetic Storms, AGU Geophys. Mon. Ser. 98, edited by: Tsurutani, B. T., Gonzalez, W. D., Kamide, Y., and Arballo, J. K., AGU, Washington, D.C., 203-225, 1997.

Gaposchkin, E. M. and Coster, A. J.: Analysis of Satellite Drag, Lincoln Laborat. J., 1, 203-224, 1988.

Gonzalez, W. D., Joselyn, J. A., Kamide, Y., Kroehl, H. W., Rostoker, G., Tsurutani, B. T., and Vasyliunas, V. M.: What is a geomagnetic storm?, J. Geophys. Res., 99, 5771-5792, 1994.

Heelis, R. A., Sojka, J. J., David, M., and Schunk, R. W.: Storm time density enhancements in the middle-latitude dayside ionosphere, J. Geophys. Res., 114, A03315, https://doi.org/10.1029/2008JA013690, 2009.

Huang, C.-S., Foster, J. C., Goncharenko, L. P., Erickson, P. J., Rideout, W., and Coster, A. J.: A strong positive phase of ionospheric storms observed by the Millstone Hill incoherent scatter radar and global GPS network, J. Geophys. Res., 110, A06303, https://doi.org/10.1029/2004JA010865, 2005.

Huba, J. D., Joyce, G., and Fedder, J. A.: Sami2 is another model of the ionosphere (SAMI2): a new low-latitude ionosphere model, J. Geophys. Res., 105, 23035-23053, 2000.

Huba, J. D., Dymond, K. F., Joyce, G., Budzien, S. A., Thonnard, S. E., Fedder, J. A., and McCoy, R. P.: Comparison of $\mathrm{O}^{+}$density from ARGOS LORAAS data analysis and SAMI2 model results, Geophys. Res. Lett., 29, 1102, https://doi.org/10.1029/2001GL013089, 2002.

Immel, T. J., Foster, J. C., Coster, A. J., Mende, S. B., and Frey, H. U.: Global storm time plasma redistribution imaged from the ground and space, Geophys. Res. Lett., 32, L03107, https://doi.org/10.1029/2004GL021120, 2005.

Kelley, M. C., Fejer, B. G., and Gonzales, C. A.: An explanation for anomalous equatorial ionospheric electric field associated with a northward turning of the interplanetary magnetic field, Geophys. Res. Lett., 6, 301-304, 1979.

Kil, H., Paxton, L. J., Pi, X., Hairston, M. R., and Zhang, Y.: Case study of the 15 July 2000 magnetic storm effects on the ionosphere-driver of the positive ionospheric storm in the winter hemisphere, J. Geophys. Res., 108, 1391, https://doi.org/10.1029/2002JA009782, 2003.

Killeen, T. L., Hays, P. B., Carignan, G. R., Heelis, R. A., Hanson, W. B., Spencer, N. W., and Brace, L. H.: Ion-neutral coupling in the high-latitude F region: Evaluation of ion heating terms from Dynamics Explorer 2, J. Geophys. Res., 89, 7495-7508, 1984.

Kosch, M. J., Cierpka, K., Rietveld, M. T., Hagfors, T., and Schlegel, K.: High-latitude ground-based observations of the thermospheric ion-drag constant, Geophys. Res. Lett., 28, 13951398, 2001.
Lakhina, G. S., Alex, S., Tsurutani, B. T., and Gonzalez, W. D.: Super magnetic storms: Hazard to the Society, in: AGU monograph on Extreme Events and Natural Hazards: The Complexity Perspective, Geophysical Monograph Series 196, edited by: Sharma, A. S., Bunde, A., Dimri, V. P., and Baker, D. N., AGU, Washington, D.C., 267-278, 2012.

Lakhina, G. S. and Tsurutani, B. T.: Geomagnetic storms: historical perspective to modern view, Geosci. Lett., 3:5, 1-11, https://doi.org/10.1186/s40562-016-0037-4, 2016.

Li, L.-S.: Perturbation effect of the Coulomb drag on the orbital elements of the earth satellite moving in the ionosphere, Acta Astronautica, 68, 717-721, 2011.

Lin, C. H., Richmond, A. D., Heelis, R. A., Bailey, G. J., Lu, G., Liu, J. Y., Yeh, H. C., and Su, S.-Y.: Theoretical study of the low- and midlatitude ionospheric electron density enhancement during the October 2003 superstorm: Relative importance of the neutral wind and the electric field, J. Geophys. Res., 110, A12312, https://doi.org/10.1029/2005JA011304, 2005.

Maehara, H., Shibayama,T., Notsu, S., Notsu, Y., Nagao, T., Kusaba, S., Honda, S., Nogami, D., and Shibata, K.: Superflares on solar-type stars, Nature Lett., 485, 478-481, https://doi.org/10.1038/nature11063, 2012.

Mannucci, A. J., Tsurutani, B. T., Iijima, B. A., Komjathy, A., Saito, A., Gonzalez, W. D., Guarnieri, F. L., Kozyra, J. U., and Skoug, R.: Dayside global ionospheric response to the major interplanetary events of October 2930, 2003 "Halloween storms", Geophys. Res. Lett., 32, L12S02, https://doi.org/10.1029/2004GL021467, 2005.

Mannucci, A. J., Tsurutani, B. T., Abdu, M. A., Gonzalez, W. D., Komjathy, A., Echer, E., Iijima, B. A., Crowley, G., and Anderson, D.: Superposed epoch analysis of the dayside ionospheric response to four intense geomagnetic storms, J. Geophys. Res., 113, A00A02, https://doi.org/10.1029/2007JA012732, 2008.

Mannucci, A. J., Tsurutani, B. T., Kelley, M. C., Iijima, B. A., and Komjathy, A.: Local time dependence of the prompt ionospheric response to the 7, 9, and 10 November 2004 superstorms, J. Geophys. Res., 114, A10308, https://doi.org/10.1029/2009JA014043, 2009.

Maruyama, T., Ma, G., and Nakamura, M.: Signature of TEC storm on 6 November 2001 derived from dense GPS receiver network and ionosonde chain over Japan, J. Geophys. Res., 109, A10302, https://doi.org/10.1029/2004JA010451, 2004.

Moe, K. and Moe, M. M.: Gas-surface interactions and satellite drag coefficients, Planet. Space Sci., 53, 793-801, 2005.

Moe, K., Moe, M. M., and Wallace, S. D.: Improved satellite drag coefficient calculations from orbital measurements of energy accommodation, J. Spacecraft Rockets, 35, 266-272, 1998.

Namba, S. and Maeda, K.-I.: Radio Wave Propagation, Corona, Tokyo, 86 pp., 1939.

Nishida, A.: Coherence of geomagnetic DP2 fluctuations with interplanetary magnetic variations, J. Geophys. Res., 73, 5549-5559, 1968.

Obayashi, T., The interaction of solar plasma with geomagnetic field, disturbed condition, in: Solar Terrestrial Physics, Vol. 107, edited by: King, J. W. and Newman, W. S., Acad. Press., London, 1967.

Pardini, C., Anselmo, L., Moe, K., and Moe, M. M.: Drag and energy accommodation coefficients during sunspot maximum, Adv. Space Res., 45, 638-650, 2010. 
Rishbeth, H., Heelis, R. A., Makela, J. J., and Basu, S.: Storming the Bastille: the effect of electric fields on the ionospheric F-layer, Ann. Geophys., 28, 977-981, https://doi.org/10.5194/angeo-28977-2010, 2010.

Sahai, Y., Fagundes, P. R., Becker-Guedes, F., Bolzan, M. J. A., Abalde, J. R., Pillat, V. G., de Jesus, R., Lima, W. L. C., Crowley, G., Shiokawa, K., MacDougall, J. W., Lan, H. T., Igarashi, K., and Bittencourt, J. A.: Effects of the major geomagnetic storms of October 2003 on the equatorial and low-latitude F region in two longitudinal sectors, J. Geophys. Res., 110, A12S91, https://doi.org/10.1029/2004JA010999, 2005.

Tsurutani, B. T. and Lakhina, G. S.: An extreme coronal mass ejection and consequences for the magnetosphere and Earth, Geophys. Res. Lett., 41, 287-292, https://doi.org/10.1002/2013GL058825, 2014.

Tsurutani, B. T., Gonzalez, W. D., Tang, F., and Lee, Y. T.: Great magnetic storms, Geophys. Res. Lett., 19, 73-76, 1992.

Tsurutani, B. T., Gonzalez, W. D., Lakhina, G. S., and Alex, S.: The extreme magnetic storm of 1-2 September 1859, J. Geophys. Res., 108, 1268, https://doi.org/10.1029/2002JA009504, 2003.

Tsurutani, B. T., Mannucci, A. J., Iijima, B., Abdu, M. A., Sobral, J. H. A., Gonzalez, W. D., Guarnieri, F., Tsuda, T., Saito, A., Yumoto, K., Fejer, B., Fuller-Rowell, T. J., Kozyra, J., Foster, J. C., Coster, A., and Vasyliunas, V. M.: Global dayside ionospheric uplift and enhancement associated with interplanetary electric fields, J.Geophys. Res., 109, A08302, https://doi.org/10.1029/2003JA010342, 2004.

Tsurutani, B. T., Judge, D. L., Guarnieri, F. L., Gangopadhyay, P., Jones, A. R., Nuttall, J., Zambon, G. A., Kidkovsky, L., Mannucci, A. J., Iijima, B., Meier, R. R., Immel, T. J., Woods, T. N., Prasad, S., Floyd, L., Huba, J., Solomon, S. C., Straus, P., and Viereck, R.: The October 28, 2003 extreme EUV solar flare and resultant extreme ionospheric effects: Comparison to other Halloween events and the Bastille Day event, Geophys. Res. Lett., 32, L03S09, https://doi.org/10.1029/2004GL021475, 2005.
Tsurutani, B. T., Verkhoglyadova, O. P., Mannucci, A. J., Araki, T., Sato, A., Tsuda, T., and Yumoto, K.: Oxygen ion uplift and satellite drag effects during the 30 October 2003 daytime superfountain event, Ann. Geophys., 25, 569-574, https://doi.org/10.5194/angeo-25-569-2007, 2007.

Tsurutani, B. T., Verkhoglyadova, O. P., Mannucci, A. J., Saito, A., Araki, T., Yumoto, K., Tsuda, T., Abdu, M. A., Sobral, J. H. A., Gonzalez, W. D., McCreadie, H., Lakhina, G. S., and Vasyliunas, V. M.: Prompt penetration electric fields (PPEFs) and their ionospheric effects during the great magnetic storm of 30-31 October 2003, J. Geophys. Res., 113, A05311, https://doi.org/10.1029/2007JA012879, 2008.

Tsurutani, B. T., Verkhoglyadova, O. P., Mannucci, A. J., Lakhina, G. S., and Huba, J. D.: Extreme changes in the dayside ionosphere during a Carrington-type magnetic storm, J. Space Weather Space Clim., 2, A05, https://doi.org/10.1051/swsc/2012004, 2012.

Vasyliunas, V. M.: The largest imaginable magnetic storm, J. Atmos. Sol. Terr. Phy., 73, 1444, https://doi.org/10.1016/j.jastp.2010.05.012, 2011.

Verkhoglyadova, O. P., Tsurutani, B. T., and Mannucci, A. J.: Temporal Development Of Dayside Tec Variations During The October 30, 2003 Superstorm: Matching Modeling To Observations, in: Advances in Geosciences, Solar Terrestrial, Vol. 8, edited by: Duldig, M., World Sci., Hackensack, NJ, 69-77, 2007.

Verkhoglyadova, O. P., Tsurutani, B. T., Mannucci, A. J., Saito, A., Araki, T., Anderson, D., Abdu, M. and Sobral, J. H. A.: Simulation of PPEF effects in dayside low-latitude ionosphere for the October 30, 2003 superstorm, in: Midlatitude Ionospheric Dynamics and Disturbances, Geophys. Mon. Ser. 181, edited by: Kintner, P., Coster, A., Fuller-Rowell, T., Mannucci, A., Mendillo, M., and Heelis, R., AGU, Washington, D.C., 169-178, 2008.

Yin, P., Mitchell, C. N., Spencer, P. S. J., and Foster, J. C.: Ionospheric electron concentration imaging using GPS over the USA during the storm of July 2000, Geophys. Res. Lett., 31, L12806, https://doi.org/10.1029/2004GL019899, 2004. 